\title{
Transmedia Storytelling and the Creation of a Converging Space of Educational Practices
}

\author{
http://dx.doi.org/10.3991/ijet.v9i6.4134 \\ Patrícia Rodrigues, José Bidarra \\ Universidade Aberta, Lisbon, Portugal
}

\begin{abstract}
As the media landscape evolves, educators are tapping into learning opportunities that meet the needs of 21 st century learners. This paper provides an entry point to a relevant social problem related to education with Transmedia Storytelling, a story that crosses multiple forms of media, and each delivers a unique or specific contribution to the story experience. This study aims to contribute to the development and application of Transmedia Storytelling in educational settings. For this purpose a set of frameworks and educational models were selected based on research that points to the widespread use of transmedia learning experiences that are authentic, engaging, immersive, as well as support the development of new literacies. Ultimately, we attempt to demonstrate how the creation of a transmedia learning environment will allow the learner to develop and thrive in the digital age.
\end{abstract}

Index Terms-Connected Learning, Game-based Learning, Location-based Learning, Transmedia Play, Transmedia Storytelling.

\section{INTRODUCTION}

Storytelling is considered to be an innate human activity. As a core element of human communication and sense making, storytelling has been studied across a wide variety of fields ranging from literary criticism, cultural studies, linguistics to education. Not only do stories enhance individual development, they also imply a sense of cultural identity. Storytelling as a learning practice is not new. Stories naturally lend themselves to learning as they "help us connect new learning to existing personal knowledge as the patterns of narrative form connections to earlier knowledge in the brain, and are contextualized by existing social norms and values "[1]. Storytelling is an engaging activity "Imaginary worlds are enjoyed not only by those who visit them, but also by those who invent." [2] and used as a learning opportunity to create content and connect to context.

The 21st Century learners have taken the ancient tradition of storytelling to a new dimension taking advantage of the rich and immersive possibilities available on the media landscape - they "do not see narrative as text-based only; rather they view narrative as a multimedia enterprise" [3]. This new generation is weaving stories across multiple platforms and expanding learning and engagement through what is referred as Transmedia Storytelling.

Transmedia Storytelling has been defined by various scholars in different academic fields of study. At the moment, there is no consensual or canonical definition and given its wide scope of application, researchers are expressing the need for an interdisciplinary space of discus- sion and proposing the constitution of an independent field of study of Transmedia Storytelling.

For the purpose of this paper, Transmedia Storytelling "represents a process where integral elements of a fiction get dispersed systematically across multiple delivery channels for the purpose of creating a unified and coordinated entertainment experience. Ideally, each medium makes it own unique contribution to the unfolding of the story." [4] - a definition proposed by Henry Jenkins in the context of a media convergence culture.

Transmedia Storytelling mirrors the dynamics existent in the media ecosystem. Media consumption has altered, and the audience is empowered to select how and where to access the story - "consumers become hunters and gatherers pulling together information from multiple sources to form a new synthesis" [5]. Digital learners are players who want to take part in creating stories and assume the protagonist role in their learning path, yet the educational system seems to neglect their context and skills or meet their learning needs. A new approach is needed, following a theoretical methodological discussion, allowing us to obtain a deeper insight on what works best in which realities, contrasting different potential perspectives.

The rupture of traditional assumptions and educational models has propelled educators into the exploration of diverse learning formats that might meet the needs of a "new learner" by incorporating new kinds of inputs, media consumption and production practices, global resources and accommodate the move into a more learner-centered environment.

The educational system needs to adapt and narrow the impact of these ongoing transformations by harnessing the power of the options available in an ever-changing media landscape. Moreover, teaching and learning have gained a new dimension outside the traditional educational institutions and opportunities are now available in an expanding learning ecosystem.

The creation of a transmedia learning environment might scaffold this change. Several elements of transmedia might be used in the design of learning experiences that create engagement and turn learners into active participants. Transmedia Storytelling involves world building and in this perspective it might extend to content world building and curricula. Herr-Stephenson \& Alper, authors of the report $T$ is for Transmedia: Learning through Transmedia Play, highlight that "transmedia can be a resource for learning in various contexts, including schools, expanded learning programs, and at home. (...) transmedia play is a way of thinking about children's experimentation with, expression through, and participation in a transmedia experience that acknowledges their 
cultural engagement, respects their thoughts and feelings and builds up and upon 21 st Century literacies" [6]. Hovious develops even further this idea by singling out seven different literacies [7] that might be found in Transmedia Storytelling projects: multimodal literacy; critical literacy; digital literacy; media literacy; visual literacy; information literacy and game literacy (problem-solving; use of logical and strategic thinking).

The following sections present a set of frameworks and educational paths through which a transmedia learning environment might emerge.

\section{CONNECTED LEARNING}

Connected Learning: An Agenda for Research and Design is a report that maps the issues and tensions concerning education within a networked media environment and provides a framework to design new learning practices. It focuses on the implications of this new media scenario and the challenges it might present in terms of learning and literacy as well as the development of "digital citizens" - "we are living in a historical moment of transformation and realignment in the creation and sharing of knowledge, in social, political and economic life, and in global connectedness" [8].

As the authors Ito et al. point out [8], Connected Learning is "reimagining education in the information age." Mishra in the report Now\&Next: Future of Engagement [9] highlights six major trends (Table I) in terms of creation and consumption of media content:

Table I.

CREATION AND CONSUMPTION OF MEDIA CONTENT

\begin{tabular}{|c|c|c|}
\hline $\begin{array}{l}\text { Short Attention } \\
\text { Spans }\end{array}$ & $\rightarrow$ & $\begin{array}{l}\text { News and entertainment are consumed in } \\
\text { byte-sized pieces on mobile devices, often } \\
\text { on-the-go }\end{array}$ \\
\hline $\begin{array}{l}\text { Narrowing of } \\
\text { Interests }\end{array}$ & $\rightarrow$ & $\begin{array}{l}\text { People filter topics based on their } \\
\text { interests }\end{array}$ \\
\hline $\begin{array}{c}\text { Social } \\
\text { Serendipity }\end{array}$ & $\rightarrow$ & $\begin{array}{l}\text { People discover new content according to } \\
\text { what is shared in their networks or by like } \\
\text { minded people, via sophisticated } \\
\text { algorithms }\end{array}$ \\
\hline $\begin{array}{l}\text { Community } \\
\text { Curation }\end{array}$ & $\rightarrow$ & $\begin{array}{l}\text { Communities emerge around a shared } \\
\text { interest or goal via content curation }\end{array}$ \\
\hline $\begin{array}{c}\text { Remix in } \\
\text { Context }\end{array}$ & $\rightarrow$ & $\begin{array}{l}\text { People remix photos, videos, music, art } \\
\text { and share creative work in the context of } \\
\text { time, place or event }\end{array}$ \\
\hline $\begin{array}{l}\text { Emergent } \\
\text { Storylines }\end{array}$ & $\rightarrow$ & $\begin{array}{l}\text { People continuosly curate their social } \\
\text { network timeline with emergent } \\
\text { narratives }\end{array}$ \\
\hline
\end{tabular}

The principles that build a Connected Learning experience embody these trends while channeling them to the fulfillment of educational goals (Table II).

Table II.

CONNECTED LEARNING

\begin{tabular}{ccl}
\hline $\begin{array}{c}\text { LEARNING } \\
\text { PRINCIPLES }\end{array}$ & $\begin{array}{c}\text { DESIGN } \\
\text { PRINCIPLES }\end{array}$ & $\begin{array}{c}\text { NEW SOCIAL MEDIA } \\
\text { TRENDS }\end{array}$ \\
Interest-powered & $\begin{array}{c}\text { Production- } \\
\text { centered }\end{array}$ & $\rightarrow \begin{array}{l}\text { People filter topics based on } \\
\text { their interests } \\
\text { Peer-supported }\end{array}$ \\
$\begin{array}{c}\text { Openly } \\
\text { networked }\end{array}$ & $\rightarrow \begin{array}{l}\text { according to what is shared } \\
\text { in their networks or by like } \\
\text { minded people } \\
\text { Communities emerge around }\end{array}$ \\
$\begin{array}{c}\text { Academically } \\
\text { oriented }\end{array}$ & Shared purpose & $\rightarrow \begin{array}{l}\text { a shared interest or goal via } \\
\text { content curation }\end{array}$ \\
\hline
\end{tabular}

Connected Learning is rooted in the active participation of learners and educators; it fosters the ability to connect people, resources and content. By assembling components, learners can build personalized pathways to accomplish educational goals - "the integration of personal inclass and out-of-class experiences, collaborations and resources leads to learning experiences that suit the learners' specific needs" [8].

In the educational landscape, the Connected Learning framework addresses challenges such as: 1) lack of connection between formal education and learners' social contexts; 2) the need for social connection- learning is meaningful when it is a part of valued social relationships and shared practice, culture, and identity; 3 ) the need to enhance civic engagement - learning environments and civic life thrive when all members actively engage and contribute.

The concept of Connected Learning is recent and therefore still lacks a more precise configuration since teachers and learners are still sorting out how to find effective ways to assemble all the options required to build a learning experience from a wide and complex scope of choices. However, there seems to be consensus among researchers in what regards the implementation of an educational shift; similarly to Connected Learning, the report System Upgrade: Realising the vision for UK education [10], addresses 12 key issues while providing recommendations for each theme: connect; share; analyze; assess; analyze; apply; personalize; engage; streamline; include; know; compute and construct. These are actions that clearly put into evidence the use of the literacies one might find in transmedia projects.

More than a resource, transmedia is a tool to be valued in the construction of expanded learning experiences that address "(...) some of the most pressing challenges facing education today. Through immersive, interconnected, and dynamic narratives, transmedia engages multiple literacies, including textual, visual, and media literacies, as well as multiple intelligences" [6]. In the report, $T$ is for Transmedia: Learning through Transmedia Play [6] it is possible to find elements that might forge a connection between the learner's media participation habits and learning.

\section{TRANSMEDIA Play}

Based on the lives of children 5 to 11 years old, the report $T$ is for Transmedia: Learning through Transmedia Play [6] identifies links between transmedia and learning bringing forward key elements of Transmedia Play and providing a set of principles for Transmedia Play experiences.

Alper and Herr-Stephenson define Transmedia Play "as a way of thinking about children's experimentation with, expression through, and participation in media" [11].

According to these authors, Transmedia Play favors learning in different ways: 1) promotes new approaches to reading, as children must learn to read both written and multimedia texts (across multiple media) and deeply (digging into the details of the narrative); 2) encourages joint media engagement, providing opportunities for families to experience transmedia together; 3) can support constructivist learning goals - it involves exploration, experimentation, and remix, which emphasize the active role of the 
learner in creating knowledge by working to make connections among information in a specific context [11].

Transmedia Play fosters learner-centered practices and is grounded on the knowledge acquired by children while playing video games, telling stories and exploring media. Transmedia Play develops literacy and promotes experiential learning since it implies:

1. Resourcefulness - creative thinking to solve challenges.

2. Sociability - communications among peers mediated by media/ technology.

3. Mobility - use of mobile devices and the movement between media platforms.

4. Accessibility - access from different points of entry and definition of a trajectory according to singular contexts and types of access.

5. Replayability - the act of revisiting and exploring worlds that require multiple visits.

Besides pointing out the pedagogical potential of Transmedia Play, the authors stress the fact that though these may act as starting points, they require further reflection among researchers, specifically on how to best leverage the possibilities of transmedia learning - "(...) under what conditions transmedia supports social skills and cultural competencies, as well as digital, textual, visual, and media literacies" [11]. Ethical and legal issues should be addressed too, namely the sharing of content online.

Transmedia Play entails another dimension targeted to a wider audience. The concept is also used to refer to ways for users to interact with their IP across multiple media devices in a variety of spaces. In other words, Transmedia Play provides moments for audiences to access multiple points of entry to a transmedia world. Transmedia games are an emergent art form and storytelling practice rising from the contemporary convergence culture. Transmedia games, like computer, video or mobile games, develop literacies that go beyond reading and writing. Given their mechanics and the multimedia interactions that constitute them, they require and develop new literacies. The following section aims to explore ways in which games may afford learning, whilst part of Transmedia Play.

\section{GAME-BASED LEARNING}

In the last two decades, video games became increasingly popular. During this time, they have been extensively studied by educational researchers to explore their potential for learning purposes. Video games, especially massively multiple online role-playing games (MMORPGs) present elements that can be used for the creation of interactive learning environments and constitute a space that fosters learning of various types of knowledge - knowledge of a world's infrastructures and world logic is important for audiences' understanding of non interactive worlds "(...) such knowledge gains new importance in an interactive world, where it can be used directly by the player who is a participant in the world whose goals and objectives cannot be completed without that knowledge" [2]. Moreover, MMPORGs engage users to participate - "Participation in an MMORPG is collaborative (...) to an extent everything that happens within an online virtual is automatically a part of that world" [2]. From this perspective, gamers are also world builders bringing forward all kind of skills to complete a goal. More than games, they are learning laboratories in which learners can experiment.

Gee argues for the importance of video games in learning [12] and suggests a set of learning principles that are built into video games; among them the author points out to the relevance of situated meaning - verbal information gains meaning when associated with images, actions, experiences and goals in the game and and highlights the fact that games are complex systems and form of model based reasoning as they encourage players to think on how variables come together so that they solve problems and accomplish goals.

Games favor the manipulation of content. They have been used in the context of different subjects ranging from history to science. Assassin's Creed, for instance, allows the learners to "replay history" [13]. In the science field, "Simulations and games have great potential to advance multiple science learning goals, including motivation to learn science, conceptual understanding, science process skills, understanding of the nature of science, scientific discourse and argumentation, and identification with science and science learning" [14]. Games are also spaces in which learners can manipulate language - "The rich multimodal environments that games provide function to ground language learning in the situated context of its meaning and use [15], thereby enabling meaningful language acquisition to take place. "They allow the grounded use of language in a rich context, both virtually and, in many cases, socially" [13].

Games are redefining the nature of learning. Video games are in fact learning scenarios in which production of knowledge takes places; such is visible in Theorycrafting. As important as the game itself are the participatory spaces constructed around it. These spaces develop collaborative processes and foster the motivation to learn. As an assessment tool, the player's logs allow to map decisions in the course of a player's problem solving process. Equally relevant to learning is the game design. It provides the support to develop the gaming experience via context and, mentoring acting as a teacher to the player. Games can also be used as creative tools allowing learners to explore worlds constructed by them. Different dimensions of the game address different aspects of the learning process such as motivation, design, assessment, and collaboration:

1. Motivation - Gee points to the fact that the game is based on the recognition that learning is a deep motivation for the human [15]. Learning within the game has to be appealing and engaging which implies, according to Gee, to explore the motivation for learning within the human.

2. Design - The game design is crucial because it lends itself to mentoring and teaching functions similarly to the teacher. It shapes the players' goals, decisions and actions but doesn't take away their freedom of choice and accountability in the decision-making process. According to Gee, it also allows the convergence of various forms of exposure, description and languages that promote the articulation of different types of knowledge in the act of play [16]. Through Scratch (a platform to create games, interactive stories, animations and music), Kafai and Peppler put into evidence that adolescents are engaged in the 
game design creative process to the extent that they develop it in their spare time spontaneously [17]. As an interactive form of art, the authors highlight three dimensions that are explored in the creation of games: technical, critical and creative and argue that the combination of the three develops gaming fluencies without the need for instructional support.

3. Assessment - Engagement in the game is paired with ongoing assessment process [16]. Games more than articulating knowledge, provide ways to assess problem-solving skills, quality of choices and decisions putting their impact into perspective in short and long term. Through query logs or discussion boards, it is possible to track the player's performance and more importantly the knowledge building process and interactions.

4. Collaborative space - Games create social engagement "most positive social engagement in and around games involves, in part, players acting and thinking like designers"[2]. Gee and Hayes point out that players create nurturing affinity spaces - "open spaces where groups of people are drawn together because of a shared interest or engagement in a common goal (...) Affinity spaces are able to bridge barriers of age, race, socio-economic status, and educational level, and thus allow each user to participate as he/she chooses" [18]. Another phenomenon emerging from games, in particular MMORPGs, is Theorycrafting - " an exemplary form of engagement with participatory media" that "entails the use of mathematics, logic, experimental design, and writing" [19]. It is a social and collaborative practice that promotes discussion and interpretation of experiments results " within the space of a single website or blog, students can publish, comment, edit and update" [19]. It is a multifaceted activity that encourages community participation and contribution.

Games are conducive to social, experiential and situated learning that may lead to the acquisition of critical thinking, development of creative and collaborative practices, as well as, put into evidence multiple perspectives, social awareness, responsibility and media fluency [20]. There is reason to believe that learner-driven demand and anticipated boost in effectiveness will facilitate an increasing uptake of serious games in the short term, even if simulations have a longer association of its use to support education and training - namely in applications for business, health, and military training. In any scenario, institutions and educators will need extra support when selecting, repurposing and using games or simulations in their practice, often trying to overcome factors such as time pressure, lack of experience, shortage of resources, etc. In many cases off-the-shelf games can be successfully introduced into educational processes, always a good decision as the creation of high-quality educational games has a prohibitive cost.

Context is a key aspect in the learning process. Location-based games, in particular, allow the player to relate knowledge with physical activities situated in the real world. Similarly, in a transmedia experience a player/user can be emerged in the storyworld via context through location-aware events - such is visible, for instance, in the campaign Unlock the 007 in you in which passengers were challenged to complete a mission in less than 70 seconds in a train station [9].

The idea of learning as context-dependent is at least a decade old, but the use of mobile devices added new meaning to the term situated learning [21]. Location-based learning is becoming one of the most pervasive uses of mobile devices, and it has increasingly become the focus of attention in the educational community. The following section aims to tap into some of the issues that are rising in this field.

\section{LOCATION-BASED LEARNING}

Location-based learning leverages the technology advancements of mobile devices - "Mobile phones are becoming context-aware, with GPS positioning, recognition of objects by infrared or wireless tags, and automatic interpretation of images. They are offering opportunities to support new forms of learning through contextual support for field trips, location-based guides, environmental studies" [22]. This rather new designation usually refers to virtual experiences played out in real world spaces. This last aspect makes a difference and identifies the genre more specifically. In general, contextualized clues can only be discovered via real world spaces with the aid of GPS devices that are becoming common amongst students these days.

Learners are active in different contexts and change their learning contexts. Addressing this issue, educators are now focused on understanding context, learning outside the classroom and how this can be supported through mobile technologies. Mobile learning or augmented reality use are not new to educators yet they aren't common practices in school - "many teachers are unaware of augmented reality games (...) and aren't prepared to use them effectively in their classrooms" [23].

Taking advantage of the use of augmented reality, Witan argues it is a tool for learning as it facilitates the visualization of abstract concepts; allows the learners to develop scientific inquiry skills, design thinking and creativity. Augmented reality eliminates barriers existent in the real world - "Through augmented reality, students are able to manipulate physical forces in ways that are impossible in real life" [23] or allow learners "to explore relationships of objects and situations that aren't accessible in the real world" [23]. It also induces learner-centered practices learners can explore at their pace and experience from different perspectives. Augmented reality can be used as a production tool. Through the Imaginary Worlds project, learners created their augmented reality games by designing virtual locations and linking them to fiduciary markers, and placing them at locations around their school [23] - more than learning facts, learners were engaged in active learning and generating new knowledge.

The advent of participatory culture transformed the way learning is mediated. It created a shift from the individual to the social and from the user to the producer. In this context, learners express their views through content creation tools and share them in a networked environment. Mobility and the development of mobile technology, as well as, the use of augmented reality brought on a new dimension - the integration of the digital with the physical world; "(...) mobility allows for the broadening of hybrid possibilities, namely bringing a digital layer to physical space where none was possible before" [24]. The impact 
of this shift is most visible in the case of storytelling. Locative storytelling applications allow a user to place story elements (digital images, videos, instructions, clues, etc.) at specific geographic locations using the applications' cartographic interface, in other words, stories can now become a situated experience in the geographic space "(...) what might be otherwise be salient but abstract information when read on a computer screen can become something potentially more impactful when consumed or engaged with on location" [24].

Witan argues that the use of creative tools such as $A u$ rasma, a mobile augmented reality application that allows a user to attach a digital piece of content to a real world marker, will enable the possibility "to hand off the creation process to students so that they can learn not only as consumers of technology but also as designers" [23]. Wagner reinforces this idea by pointing out that using "Aurasma to scaffold narrative game design and situated learning experiences suggests that augmented reality has a strong affordance for supporting creative expression in situ" [24].

For mobile learning, we should look for those augmented reality eco-systems that can be used in daily learning activities. They should be open source, or free, and userfriendly since they are going to be used by teachers that in general do not have programming knowledge. With current augmented reality technology, it is already possible to create augmented reality content to layer over educational materials. For example, the teacher can use QR or Microsoft tags to add a layer with text information or a link to a web page in a printed homework sheet providing additional information to students. The creation of location-based learning experiences requires the examination how contexts for learning are created through continual interactions between people, technology, and settings [25] and how they can be supported and maintained. The challenge lies in how to promote effective interactions between learners and the physical environment.

It becomes clear through the analysis of different educational frameworks and pedagogical approaches, such as location-based learning that there is an effort to bridge the gap between formal and informal learning environments and to reach learners taking into account their context. Nevertheless this shift implies a series of challenges in what regards its implementation. Educators need to reflect upon the emerging trends in education and what has already been accomplished on the field so that they can best suit the needs of the learners they have in their classroom. The following section aims at providing examples of immersive educational projects that encourage the restructuring of teaching and learning practices through Transmedia Storytelling.

\section{TRANSMEDIA STORYTELLING EXPERIMENTS}

Transmedia learning allows educators to combine the affordances of digital technologies with learners' real life experiences and apply learner-focused pedagogies. It applies storytelling techniques combined with the use of multiple platforms to create an immersive learning landscape, which enables multivarious entry and exit points for learning and teaching [26]. In the case of the digital novel Inanimate Alice, a transmedia resource, learners engage in the participatory practice of creating episodes for the series. The educational project by Kate Pullinger and Chris Joseph presents a universe that unravels across different media platforms. In terms of structure, the authors used a spiral approach. Within each series, five in total, the episodes become gradually more complex but allow the learner to visit and revisit the story at appropriate times and places within their learning development [26].

Alice's adventures take place in a game like world, in which learners are "direct participants in helping the story to unfold across multiple platforms" [26]. It is an interactive audiovisual experience that integrates games and puzzles to enhance the storyline. Interactivity is embedded in the story through Baxi, Alice's handheld device, and Brad, Alice's virtual friend, with whom she chats on the Baxi. The integration of these elements gives the user autonomy to explore the story, unfold it in different directions and provides different entrance and exit points to the story.

Learners take part in Alice's world by co-creating content. They have access to the photo story pages, individual frames, scripts, music tracks and comic book art - resources that they can mash up and use to enhance their photos, drawings and texts. The creators have also integrated a content production tool - Snappy, an Adobe Air application, that allows learners to create interactive web presentations including text, images and audio. The project also provides means to distribute and share the learners' artifacts via applications for iPad, iPhone, Kindle Fire and Android. This allows the learners not only "to be individual producers but also to engage on collaborative sharing, joint creativity and proliferation of knowledge across the globe" [26].

Inanimate Alice's episodes can be used to explore content in different subject areas. The project includes lessons, lesson plans and multimedia components that can be used on an interactive whiteboard. Educational communities are also connected through the social learning platform Edmodo. Alice's story also addresses the topic of global citizenship - she is a citizen of the world and learners can connect with Alice's multicultural life and friends as she travels the world and is faced with cultural challenges and issues.

The project Inanimate Alice encourages teachers and learners to step beyond the story and explore it in relation to the learner's environment; it encourages the use of a broad spectrum of media literacy skills. It promotes the creation of a dynamic learning ecosystem in which educators can use different learning models and explore a wide variety of topics in order to suit the learners' needs.

Aimed at creating opportunities for exploration, interpretation and expansion through an immersive learning experience, the project Aventuras no Guadiana [27] experimented with the use of a gamebook. It is targeted to the Portuguese elementary learners and seeks to promote collaborative, engaging and effective practices to explore content in the social studies area.

The gamebook is an interactive ebook that combines the features of an ebook with those of games. Aventuras no Guadiana provides different entry and exit points to the story and encourages the learners to explore geographic and environmental elements related to the river Guadiana. To engage the learners, a set of tasks is provided to unfold the story, as they explore widgets, videos, multiplechoice quizzes and other multimedia elements. The crea- 
tors of this prototype, Bidarra et al. [27] stress the need to integrate a multimedia dimension in the artifact so that it can generate multisensory experiences thus becoming more immersive. Ultimately, the creators seek to empower the learner to define the path to discovering and unfold the story.

Examples of other story worlds that might provide context and scaffold immersive learning experiences are: Rockford's Rock Opera, targeted to pre-school and elementary learners; the transmedia mystery series Ruby Skye $P i$ that combines web episodes, games and character sites or Collapsus: The Energy Risk Conspiracy, a documentary with a fictional storyline that uses game elements.

\section{Closing Discussion}

This article sought to highlight and gather perspectives, across a variety of educational fields of study that may be used to ground the creation of a transmedia learning experience.

In the digital age, educators are confronted with significant disruptions: a changing media landscape; the rupture with traditional forms to deliver instruction, as well as, a fast paced development of mobile technologies and the inherent impact on the educational context. Nevertheless, this new era brought forward unprecedented possibilities to develop learning and numerous forms to design learning experiences.

The learning frameworks and learning models presented show a consensus when it comes to designing a learning experience - it must be engaging, encourage collaboration, develop creative thinking and problem- solving skills. All of these are on high demand if one takes into consideration the interconnected and media-charged context of the learner.

Assuming that the goal of an educator is to prepare learners with knowledge and skills so they thrive in the "real world," one has first to identify what the challenges of that world are and adjust the learning process according to it. Transmedia Play research is grounded in children's interactions with the media around them and their learning design principles are in accordance with that reality. Similarly, Connected Learning picks up from the ways teenagers interact on social networks and express themselves through the creation of artifacts online to channel these processes to learning goals. The research field of Gamebased Learning has provided evidence over two decades that games cultivate essential developmental skills in players and addressing the mobility of learners and the increased use of augmented reality applications, Locationbased learning presents strategies to use it in an learning environment. It is, in fact, meeting the learners' needs according to their context.

Transmedia projects, like Inanimate Alice, show that the creation of such story worlds can be used for the fulfillment of educational goals and support the implementation of strategies that combine effective storytelling with transmedia techniques. They reach out to learners on their terms, creating enhancing and spreading content in a rich and fruitful way. The evidence gathered also suggests that the creation of a transmedia learning environment asks for an urgent redefinition of curricular learning, taking learning processes closer to the actual contexts where people socialize, entertain and learn in informal ways.

\section{REFERENCES}

[1] S. J. Warren, J. S. Wakefield, and L. A. Mills, "Learning and teaching as communicative actions: Transmedia storytelling", Cutting-edge Technologies in Higher Education, no.6, pp. 67-94, 2013.

[2] M. J. P. Wolf, Building Imaginary Worlds: The Theory and History of Subcreation. Routledge, 2013.

[3] E. Bonsignore, A. J. Quinn, A. Druin, and B. Bederson, "Sharing stories 'in the wild': A mobile storytelling case study using StoryKit", ACM Transactions on Computer-Human Interaction (TOCHI), vol. 20, no. 3, p. 18, 2013. http://dx.doi.org/10.1145/ 2491500.2491506

[4] H. Jenkins, "Transmedia 202: Further Reflections", Confessions of an Aca-fan, http://henryjenkins.org/2011/08/-defining trans media furt her re.html. 2011.

[5] H. Jenkins, "Confronting the Challenges of a Participatory Culture (Part Six)", Confessions of an Aca-fan, http://henryjenkins.org/ 2006/10/confronting_the_challenges_of_5.html. 2006 .

[6] R. Herr-Stephenson and M. B. Alper T is for Transmedia: Learning Through Transmedia Play. USC: Annenberg Innovation Lab, 2013.

[7] A. Hovious, "The 7 Literacies of Transmedia Storytelling", http://designerlibrarian.wordpress.com/2013/11/21/the-7literacies-of-transmedia-storytelling/\#comment-1271. 2013.

[8] M. Ito, K. Gutiérrez, S. Livingstone, B. Penuel, J. Rhodes, K. Salen, J. Schor, J. Sefton-Green and S. Craig Watkins, Connected Learning: An Agenda for Research and Design. Irvine, CA: Digital Media and Learning Research Hub, 2013.

[9] MSL Group, "Now \& Next: Future of Engagement", http://peopleslab.mslgroup.com/peoplesinsights/annual-report/. 2013.

[10] R. Noss, R. Cox, D. Laurillard, R. Luckin, L. Plowman, E. Scanlon, and M. Sharples, System Upgrade - realising the Vision for UK education, London Knowledge Lab, ESRC/EPSRC Technology Enhanced Learning Programme, 2012.

[11] M. Alper and R. Herr-Stephenson, "Transmedia play: Literacy across media.", Journal of Media Literacy Education, vol 5, no. 2, 2013.

[12] J. P. Gee, "Good video games and good learning.", Phi Kappa Phi Forum, vol. 85 , no. 2, THE HONOR SOCIETY OF PHI KAPPA PHI, p.33,2005.

[13] C. Steinkuehler and K. Squire, "Videogames and Learning", Cambridge Handbook of the Learning Sciences, Second Edition, NewYork, NY: Cambridge University Press, submitted for publication.

[14] National Research Council, Learning science through computer games and simulations. Washington, DC: National Academies Press, Board on Science Education, Division of Behavioral and Social Sciences and Education, 2011.

[15] J. P. Gee and E. R. Hayes, Women and gaming: The Sims and 21 st century learning. New York: Palgrave Macmillan, 2010. http://dx.doi.org/10.1057/9780230106734

[16] J. P. Gee, "Foreword", Games, Learning, and Society: Learning and Meaning in the Digital Age, C. Steinkuehler, K. Squire, and S. Barab, eds., Cambridge University Press, 2012. http://dx.doi.org/10.1017/CBO9781139031127.002

[17] Y. B. Kafai and K. A. Peppler, "Developing Gaming Fluencies with Scratch: Realizing Game Design as an Artistic Process In the Twenty-First Century", Games, Learning, and Society: Learning and Meaning in the Digital Age, C. Steinkuehler, K. Squire, and S. Barab, eds., Cambridge University Press, pp.355-358, 2012. http://dx.doi.org/10.1017/CBO9781139031127.026

[18] J. P. Gee, and E. Hayes, "Nurturing Affinity Spaces and GameBased Learning", Games, Learning, and Society: Learning and Meaning in the Digital Age, Constance Steinkuehler, Kurt Squire, and Sasha Barab, eds., Cambridge University Press, p.123, 2012.

[19] T. Choontanom and B. Nardi, "Theorycrafting: The Art and Science of Using Numbers to Interpret the World", Games, Learning, and Society: Learning and Meaning in the Digital Age, Constance Steinkuehler, Kurt Squire, and Sasha Barab, eds., Cambridge University Press, pp.185-187, 2012. 
[20] C. Sintoris, N. Yiannoutsou, S. Demetriou, and N. Avouris, "Discovering the invisible city: Location-based games for learning in smart cities", Interaction Design and Architecture(s) Journal, no. 16, pp.47-64, 2013.

[21] J. Lave and E. Wenger, Situated learning: Legitimate Peripheral Participation. Cambridge, UK: Cambridge University Press, 1991. http://dx.doi.org/10.1017/CBO9780511815355

[22] K. Squire and E. Klopfer, "Augmented Reality Simulations on Handheld Computers.", The Journal of the Learning Sciences, vol. 16, no. 3, pp.317-413, 2007. http://dx.doi.org/10.1080/10 $\underline{508400701413435}$

[23] D. Witan, "Augmented Reality Games in Education", GLS 9.0 Conference Proceedings, p.356, http://press.etc.cmu.edu/content/ gls-90-conference-proceedings. 2013.

[24] L. Wagner and I. Erickson, "Augmented Reality and Neighborhood Narratives." GLS 9.0 Conference Proceedings, p.352, http://press.etc.cmu.edu/content/gls-90-confe-renceproceedings.2013.

[25] M. Sharples, M. Milrad, I. Arnedillo-Sánchez, and G. Vavoula, "Mobile Learning: Small devices, Big Issues.", Technology Enhanced Learning: Principles and Products, N. Balacheff, S. Ludvigsen, T. D. Jong, A. Lazonder and S. Barnes, eds., Heidelberg: Springer, pp.233-249, 2009.

[26] L. Fleming,"Expanding Learning Opportunities with Transmedia Practices: Inanimate Alice as an Exemplar.", Journal of Media Literacy Education, vol. 5, no.2, p.3, 2013.

[27] J. Bidarra, M. Figueiredo, S. Valadas, and C. Vilhena, "O gamebook como modelo pedagógico: Investigação e desenvolvimento de um protótipo para iPad", Aprender na era digital: Jogos e mobile-learning, A. Carvalho, eds, Santo Tirso: DeFacto, pp.83-109, 2012

\section{AUTHORS}

P. Rodrigues is a Digital Media Arts Ph.D. student at Universidade Aberta (the Portuguese Open University in
Lisbon). Her research interests include transmedia storytelling and educational practices. She is an E.F.L. teacher and a secondary education teaching professional. She has completed an English and German Teacher Training Degree and a Post-Graduation in Information and Communications Technology. She is currently a researcher and member of CIAC (Center for the Arts and Communication Research, University of Algarve). E-mail: patriciarbrodrigues@gmail.com.

J. Bidarra, has a Ph.D. in Educational Communications from Universidade Aberta (the Portuguese Open University), where he is currently Assistant Professor in the Department of Science and Technology. He is head of the Informatics, Physics and Technology Section (SIFT), and coordinator of a master degree in multimedia. His current research interests focus mainly on the application of multimedia and digital media in distance education, including ebooks, games and simulations. Many of his master and doctorate students are developing new methodologies to engage learners in effective experiences with digital media. Most of the research is conducted at Universidade Aberta and at CIAC (Center for the Arts and Communication Research, University of Algarve); other research includes a recent fellowship at the University of Wisconsin - Madison (USA). E-mail: Jose.Bidarra@uab.pt

Submitted 21 August 2014. Published as resubmitted by the authors 08 December 2014. 